\title{
Cutting Forces and Surface Roughness in Face-Milling of SKD61 Hard Steel
}

\author{
Tien Dung Hoang - Nhu-Tung Nguyen* - Đuc Quy Tran - Van Thien Nguyen \\ Hanoi University of Industry, Vietnam
}

This experimental study investigated the effects of milling conditions on cutting forces and finished surface roughness. The face-milling processes were performed using heat-treated SKD61 steel at a hardness of 46 HRC. With three controllable factors/levels (cutting speed, axial depth of cut, and feed rate), the most suitable orthogonal array $L_{27}$ was performed with four performance measurements that are amplitudes of cutting forces in three directions (feed, normal, and axial) and surface roughness. With ANOVA analysis, the effect of cutting conditions on the amplitudes of cutting forces and surface roughness were analysed and modelled. The most suitable regression of the cutting force's amplitudes and surface roughness was a quadratic regression with the confidence level is more than $93.74 \%$, and they were successfully verified via experimental results with very promising results. The relationship between cutting force and surface roughness was also investigated. Furthermore, using the Taguchi and ANOVA methods, the optimization process of surface roughness was performed with very close results (different of surface roughness about $4.58 \%$ ). The approach method of the present study can be applied in industrial machining to improve the surface quality in finish face-milling the SKD61 hard steel.

Keywords: surface roughness, cutting force, Taguchi method, ANOVA method, SKD61

Highlights

- The effect of cutting conditions on cutting forces and surface roughness were investigated in the face-milling of SKD61 hard steel.

- $\quad$ The surface roughness and cutting forces were modelled with quadratic regression, and these models were successfully verified with the experimental results.

- $\quad$ The relationship between cutting force and surface roughness was also investigated.

- The optimization process of surface roughness was performed and can be applied in industrial machining to improve the surface quality.

\section{INTRODUCTION}

Milling is one of the most critical processes in the manufacturing industry. In the milling process, a reliable quantitative prediction of cutting forces is critical to predicting the power and torque requirements (choice of electric motor), machine-tool vibrations, surface quality, geometrical accuracy, etc. However, given the power, surface quality, productivity, and stability are limited by milling process defects, such as deflection and chatter regeneration resulting from cutting forces.

The cutting forces were modelled depending on the tool geometry, cutting conditions, and the interaction of tool and workpiece (cutting force coefficients). This method has been used for the modelling of cutting forces in many machining processes, such as turning [1], drilling [2], and milling [3] and [4].

In milling processes, with both cutting force modelling theories and experiments, the cutting forces had been modelled and verified for many tool types such as flat-end mill [5] to [7], ball-end mill [8] and [9], bull-end mill [10], and general-end mill [11].
In these research studies, the cutting force values were predicted for each rotation angle of the tool. This method could show details of the cutting forces for each revolution of the tool, but the number of calculations was very large. However, this method could only be applied for short milling processes having several tool revolutions. Furthermore, many coefficients, such as cutting force coefficients and friction coefficients, must be obtained via experimental methods. Therefore, this method consumed a lot of time, effort and money. A simple experimental method is proposed in this paper to investigate the dynamic cutting forces and surface roughness by using the Taguchi method and ANOVA analysis to shorten the processing time.

The Taguchi method and ANOVA analysis have been widely used in industrial engineering analysis. Moreover, the Taguchi method employs a special design of orthogonal array by reducing the number of experiments to investigate the effect of the entire range of machining parameters. Recently, this method has been widely employed in several industrial fields and research work. ANOVA analysis was used to research the effect of main machining parameters 
such as machining polarity, peak current, pulse duration, among others, on the wire-cut electrical discharge machining (WEDM) characteristics such as material removal rate, surface roughness [12] and [13]. Tsoukalas [14] and Hsu and Do [15] used an $\mathrm{L}_{27}$ orthogonal array of Taguchi method to determine the optimum conditions leading to minimum porosity in aluminium alloy die castings. Rao and Padmanabhan [16] applied the Taguchi method and ANOVA in the optimization of process parameters for metal removal rate in electrochemical machining of $\mathrm{Al} / 5 \% \mathrm{SiC}$ composites. Furthermore, the Taguchi method and ANOVA analysis were also applied to investigate other machining processes, such as abrasive waterjet cutting [17], turning [18] and [19], drilling [20] to [22], and milling [23] to [25].

The surface roughness and cutting force are important machining characteristics for evaluating the productivity of machining processes. In milling processes, by using Taguchi method and ANOVA analysis, the cutting forces and surface roughness could be investigated based on a number of factors, such as depth of cut, feed rate, cutting speed, cutting time, workpiece hardness, etc. Several research works had been conducted in different conditions and had also been applied for different workpieces and tool materials, such as Kivak [26], Ozcelik and Bayramoglu [27], Turgut et al. [24], Karakas et al. [28], and Jayakumar et al. [29].

However, although there have already been many studies on cutting forces and surface roughness, it seems that the essential values such as the amplitude of cutting forces in milling processes have not been mentioned. These values can be used to predict the power consumption, energy, and the strength of the tool material needed. Besides, the relationship between cutting forces and surface roughness seems not to have been studied in previous research studies.

In this study, the influence of cutting conditions on the surface roughness and the amplitude of cutting force was investigated when face milling the SKD61 hard steel. The main contributions of this study are in three aspects: (1) Evaluate the effect of cutting conditions on surface roughness and cutting force amplitude, (2) Evaluate the tendency of surface roughness and cutting force amplitudes when cutting conditions change, and (3) determine the optimal cutting conditions by different methods.

\section{EXPERIMENTAL METHOD}

\subsection{The Experiment Setup}

\subsubsection{Workpiece and Tool}

During hard milling processes, in order to investigate the influence of machining conditions on the cutting force and surface roughness, a series of face finished milling experiments were performed. The cutter and workpiece were chosen as follows. Cutter: A Sandvik Coromant R390-020A20-11L CoroMill 390 Square Shoulder Milling Cutter, with number of inserts $N=$ 2 , a tool cutting edge angle of $90^{\circ}$, a ramping angle maximum of $5.5^{\circ}$, and a diameter of $20 \mathrm{~mm}$. Insert: Sandvik Coromant R390-11 T3 08m-pl 4220 Milling Insert, cutting edge effective length of $10 \mathrm{~mm}$, corner radius of $0.8 \mathrm{~mm}$, Coating $(\mathrm{CVD} \mathrm{Ti}(\mathrm{C}, \mathrm{N})+$ $\left.\mathrm{Al}_{2} \mathrm{O}_{3}+\mathrm{TiN}\right)$.

The workpiece (dimensions of $70 \mathrm{~mm} \times 50 \mathrm{~mm}$ $\times 15 \mathrm{~mm}$ ) material was SKD61, and its compositions are listed in Table 1. The properties of the SKD61 were: Hardness 46 HRC, Young's modulus $=210$ $\mathrm{GPa}$, Density $=7.8 \mathrm{~g} / \mathrm{cm}^{3}$.

Table 1. Chemical composites of SKD 61

\begin{tabular}{lcccccc}
\hline Element & $\mathrm{C}$ & $\mathrm{Si}$ & $\mathrm{Mn}$ & $\mathrm{Cr}$ & $\mathrm{Mo}$ & $\mathrm{V}$ \\
\hline Composite & 0.32 & 0.18 & \multirow{2}{*}{0.5} & 4.5 & 1.0 & 0.8 \\
{$[\%]$} & to 0.42 & to 1.2 & & to 5.5 & to 1.5 & to 1.2 \\
\hline
\end{tabular}

\subsubsection{Machine Set-Up and Cutting Force Measurements}

The experiments were performed at a five-axis vertical machining centre (DMU 50 - 5 Axis Milling). All experiments were performed under dry machining conditions. A dynamometer (Kistler Type 9139AA: Force Ranges: $(-3 \mathrm{kN}$ to $3 \mathrm{kN})$, data processing box, and a PC were used to measure cutting forces. The detail is illustrated in Fig 1.
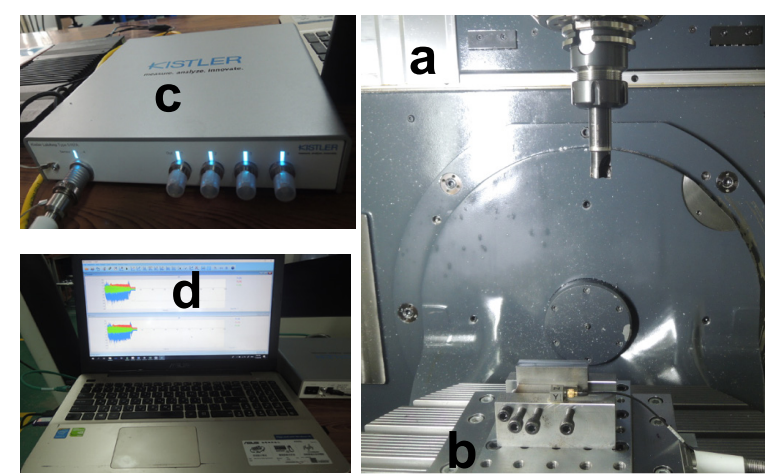

Fig. 1. Setting of cutting force measurement; a) CNC machine, b) dynamometer, c) processing box, and d) PC and display system 
The amplitudes of cutting forces were measured in three directions (feed, normal, and axial), as shown in Fig. 2. Each measurement was repeated three times following the cutting test repeated three times. The values of the measurements were stored and analysed.

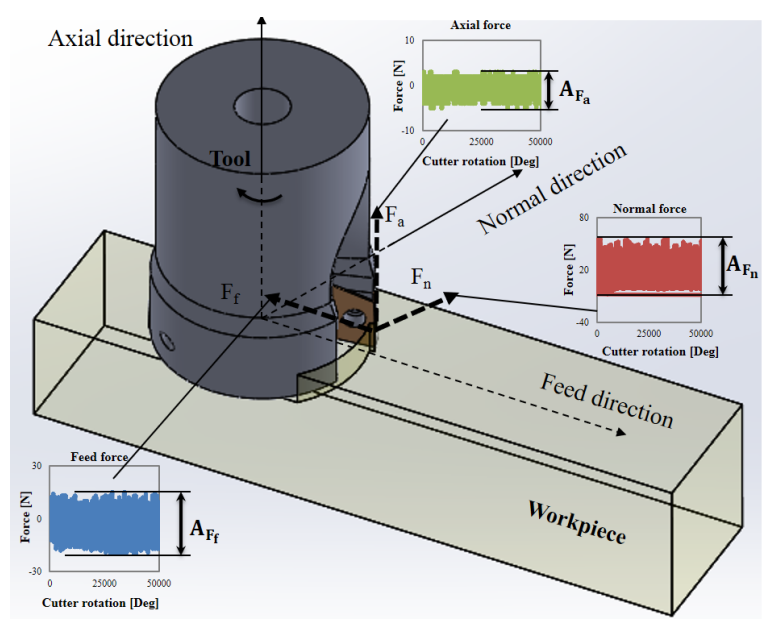

Fig. 2. Amplitudes of cutting forces in three directions

\subsubsection{Surface Roughness Measurements}

The surface roughness $\left(R_{a}\right)$ of the product was measured with a MITUTOYO-Surftest SJ-210 Portable Surface Roughness Tester (Japan). The cut-off length and evaluation length were fixed at $0.8 \mathrm{~mm}$ and $4 \mathrm{~mm}$, respectively. The surface roughness was measured parallel to the machined surface from three different points and repeated three times following three repeated times of each cutting test. The average values of the measurements were evaluated.

\subsection{Taguchi Method and Experiment Design}

The Taguchi method was developed by Genuchi Taguchi; it is a statistical method used to improve the product quality and is commonly used in improving industrial product quality due to its proven success. It is an experimental design and also a beneficial technique for high quality system design. In engineering analysis, the Taguchi method is a powerful method that has been widely used around the world. This method dramatically reduces the number of experiments by using orthogonal arrays and minimizes the effects of factors that cannot be controlled [30].

In this research, the cutting speed $\left(V_{c}\right)$, axial depth of cut $(a)$, feed rate $\left(f_{t}\right)$ were selected as control factors, and their levels were expressed in Table 2. In the experimental layout plan, with three factors and three levels, the most suitable orthogonal array $\left(\mathrm{L}_{27}\right)$ was chosen to analyse the influence of machining parameters on the surface roughness and cutting force [31]. The experimental plan was performed with 27 experiments and detailed as in Table 3. Furthermore, the response surface methodology (RSM) technique has been used for the design of experiments and analysis of experimental results [32]. RSM is used to model and analyse the response variables that are influenced by several controllable input variables. Then, RSM is generated as an interaction between statistical and mathematical techniques [33].

Table 2. Milling parameters and their levels

\begin{tabular}{llccc}
\hline No. & Machining parameters & Level 1 & Level 2 & Level 3 \\
\hline 1 & Cutting speed, $V_{c}[\mathrm{~m} / \mathrm{min}]$ & 80 & 140 & 200 \\
\hline 2 & Axial depth of cut, $a[\mathrm{~mm}]$ & 0.1 & 0.3 & 0.5 \\
\hline 3 & Feed rate, $f_{t}[\mathrm{~mm} /$ flute] & 0.05 & 0.10 & 0.15 \\
\hline
\end{tabular}

Table 3. The experimental design and results with an orthogonal array of Taguchi $L_{27}$

\begin{tabular}{cccccccc}
\hline & \multicolumn{3}{c}{ Input factors } & \multicolumn{3}{c}{ Performance measures } \\
\cline { 2 - 8 } & $V_{c}$ & $a$ & $f_{t}$ & $\begin{array}{c}R_{a} \\
{[\mu \mathrm{m}]}\end{array}$ & $\begin{array}{c}A_{F_{f}} \\
{[\mathrm{~N}]}\end{array}$ & $\begin{array}{c}A_{F_{n}} \\
{[\mathrm{~N}]}\end{array}$ & $\begin{array}{c}A_{F} \\
{[\mathrm{~N}]}\end{array}$ \\
\hline 1 & 80 & 0.1 & 0.05 & 0.166 & 70.8 & 36.3 & 78.3 \\
\hline 2 & 80 & 0.1 & 0.10 & 0.338 & 97.1 & 53.6 & 126.8 \\
\hline 3 & 80 & 0.1 & 0.15 & 0.418 & 114.9 & 71.5 & 214.4 \\
\hline 4 & 80 & 0.3 & 0.05 & 0.215 & 166.6 & 91.6 & 184.4 \\
\hline 5 & 80 & 0.3 & 0.10 & 0.309 & 212.6 & 126.4 & 276.1 \\
\hline 6 & 80 & 0.3 & 0.15 & 0.422 & 267.6 & 158.3 & 317.1 \\
\hline 7 & 80 & 0.5 & 0.05 & 0.185 & 248.5 & 134.1 & 197.7 \\
\hline 8 & 80 & 0.5 & 0.10 & 0.311 & 364.7 & 193.8 & 225.1 \\
\hline 9 & 80 & 0.5 & 0.15 & 0.473 & 436.1 & 241.7 & 266.9 \\
\hline 10 & 140 & 0.1 & 0.05 & 0.174 & 74.6 & 37.2 & 157.1 \\
\hline 11 & 140 & 0.1 & 0.10 & 0.359 & 105.6 & 59.2 & 232.9 \\
\hline 12 & 140 & 0.1 & 0.15 & 0.419 & 125.8 & 73.3 & 314.5 \\
\hline 13 & 140 & 0.3 & 0.05 & 0.168 & 187.4 & 87.0 & 198.7 \\
\hline 14 & 140 & 0.3 & 0.10 & 0.287 & 240.4 & 123.9 & 306.0 \\
\hline 15 & 140 & 0.3 & 0.15 & 0.392 & 329.0 & 168.3 & 400.6 \\
\hline 16 & 140 & 0.5 & 0.05 & 0.183 & 280.9 & 135.2 & 266.8 \\
\hline 17 & 140 & 0.5 & 0.10 & 0.372 & 376.0 & 195.2 & 357.5 \\
\hline 18 & 140 & 0.5 & 0.15 & 0.435 & 434.2 & 235.7 & 446.4 \\
\hline 19 & 200 & 0.1 & 0.05 & 0.192 & 124.5 & 58.1 & 192.9 \\
\hline 20 & 200 & 0.1 & 0.10 & 0.354 & 153.8 & 74.2 & 275.8 \\
\hline 21 & 200 & 0.1 & 0.15 & 0.413 & 176.8 & 84.4 & 341.2 \\
\hline 22 & 200 & 0.3 & 0.05 & 0.200 & 202.2 & 94.1 & 253.1 \\
\hline 23 & 200 & 0.3 & 0.10 & 0.329 & 291.2 & 133.2 & 386.4 \\
\hline 24 & 200 & 0.3 & 0.15 & 0.444 & 355.7 & 175.6 & 447.6 \\
\hline 25 & 200 & 0.5 & 0.05 & 0.305 & 281.4 & 122.7 & 349.5 \\
\hline 26 & 200 & 0.5 & 0.10 & 0.444 & 466.3 & 175.4 & 431.2 \\
\hline 27 & 200 & 0.5 & 0.15 & 0.492 & 528.9 & 253.9 & 574.4 \\
\hline & & & & & & & \\
\hline 13 & & & & \\
\hline$y y y y$ &
\end{tabular}




\section{RESULTS}

\subsection{Analysis for Surface Roughness}

\subsubsection{Analysis of Variance (ANOVA) for Surface Roughness}

The experimental results were investigated and listed in Table 3. In this study, ANOVA was used to analyse the influence of cutting speed, axial depth of cut, and feed rate on the surface roughness and amplitudes of cutting forces. This analysis was performed with a $95 \%$ confidence level and a $5 \%$ significance level. This indicates that the obtained models are considered to be statistically significant. The coefficient of determination $\left(R^{2}\right)$ is defined as the ratio of the explained variation to the total variation and is a measure of the fit degree. When $R^{2}$ approaches unity, it indicates a good correlation between the experimental and the predicted values.

Table 4. Results of ANOVA for surface roughness

\begin{tabular}{lcccrcc}
\hline $\begin{array}{l}\text { Number of obs: } 27 \\
\text { Root MSE: } 0.0209\end{array}$ & & \multicolumn{3}{c}{$\begin{array}{c}\text { R-squared: } 0.9881 \\
\text { Adj R-squared: } 0.9613\end{array}$} \\
\hline Source & SS & DOF & MS & F-value & $\begin{array}{c}\text { Prob } \\
>\text { F }\end{array}$ & $\begin{array}{c}\text { Contribution } \\
{[\%]}\end{array}$ \\
\hline Model & 0.2904 & 18 & 0.0161 & 36.91 & 0.0000 \\
\hline$V_{c}$ & 0.0097 & 2 & 0.0049 & 11.13 & 0.0049 & 3.30 \\
\hline$a$ & 0.0121 & 2 & 0.0061 & 13.88 & 0.0025 & 4.12 \\
\hline$f_{t}$ & 0.2545 & 2 & 0.1273 & 291.1 & 0.0000 & 86.59 \\
\hline$V_{c} \times a$ & 0.0087 & 4 & 0.0022 & 4.99 & 0.0258 & 2.96 \\
\hline$V_{c} \times f_{t}$ & 0.0024 & 4 & 0.0006 & 1.35 & 0.3306 & 0.82 \\
\hline$a \times f_{t}$ & 0.0030 & 4 & 0.0008 & 1.69 & 0.2445 & 1.02 \\
\hline Error & 0.0035 & 8 & 0.0004 & & & 1.19 \\
\hline Total & 0.2939 & 26 & 0.0113 & & & 100 \\
\hline
\end{tabular}

In Table 4, the contributions of each factor on surface roughness were listed in the last column. It is clear from the results of ANOVA that the most important factor affecting the surface roughness was feed rate $(86.59 \%)$. The other factors differently affect surface roughness. The second factor influencing surface roughness was the axial depth of cut $(4.12 \%)$. The third factor influencing on the surface roughness was cutting speed $(3.3 \%)$.

\subsubsection{Regression and Verification of Surface Roughness Model}

The regression analysis was used to model and analyse the relationship between a dependent variable and one or more independent variables. In this study, three dependent variables are surface roughness and amplitudes of cutting force in three directions (axial, feed, normal), whereas the independent variables are cutting speed $\left(V_{c}\right)$, axial depth of cut $(a)$, and feed rate $\left(f_{t}\right)$. By using Intercooled Stata $8.2^{\mathrm{TM}}$ software, the most suitable regression of surface roughness was a quadratic regression, as given in Eq. (1).

$$
\left\{\begin{aligned}
R_{a}= & 0.1143-0.0018 \times V_{c}-0.5515 \times a+4.9692 \times f \\
& +0.0016 \times V_{c} \times a-0.0026 \times V_{c} \times f_{t} \\
& +0.0750 \times a \times f+0.00007 \times V_{c}^{2} \\
& +0.6958 \times a^{2}-11.3333 \times f_{t}^{2} \\
R^{2} & =95.85 \%, R_{A d j}^{2}=93.66 \% \\
& R_{A d j}^{2} \text { is the Adjusted } R^{2}
\end{aligned}\right.
$$

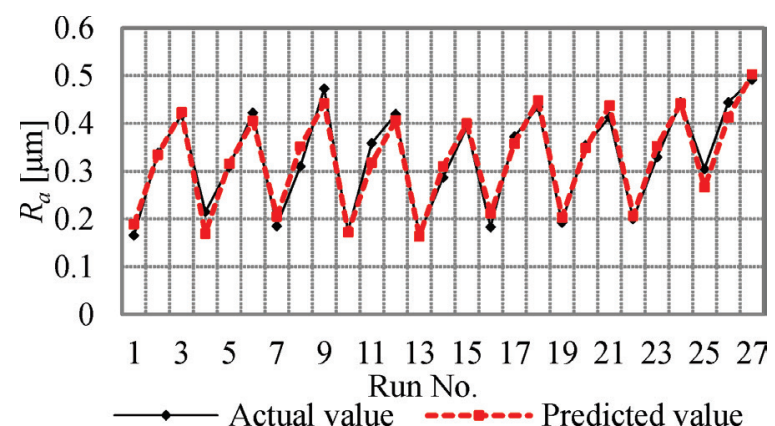

Fig. 3. Measured and predicted results of surface roughness

The verification results of the surface roughness model were described in Fig. 3. As seen from this figure, the predicted results were very close to the experimental results. There is a very good relation between predicted values and test values. The $R^{2}$ values of the equations obtained by the quadratic regression model for surface roughness were found to be $95.85 \%$. These results showed that the quadratic regression model was shown to be successfully investigated regarding surface roughness in the facemilling processes of SKD61 hard steel.

\subsubsection{Parametric Influence on Surface Roughness}

The variation of surface roughness corresponding to the axial depth of cut, feed rate, and cutting speed was described in Fig 4. The consequences of the axial depth of cut and federate on surface roughness for three cutting speed as $80 \mathrm{~m} / \mathrm{min}, 140 \mathrm{~m} / \mathrm{min}$, and $200 \mathrm{~m} / \mathrm{min}$, respectively. It is very clear that surface roughness increases with increasing feed rate. This trend can be explained that when feed rate increases, that results in an increase in undeformed chip thickness, and undeformed chip thickness is directly proportional to cutting forces. Then, when 
the cutting forces increase, the stability and damping characteristics of the machine-tool system will be affected, which makes more vibrations and ultimately affects the surface roughness. This result is similar to the result of the change in the surface roughness that is noted in several works such as [34] and [35].

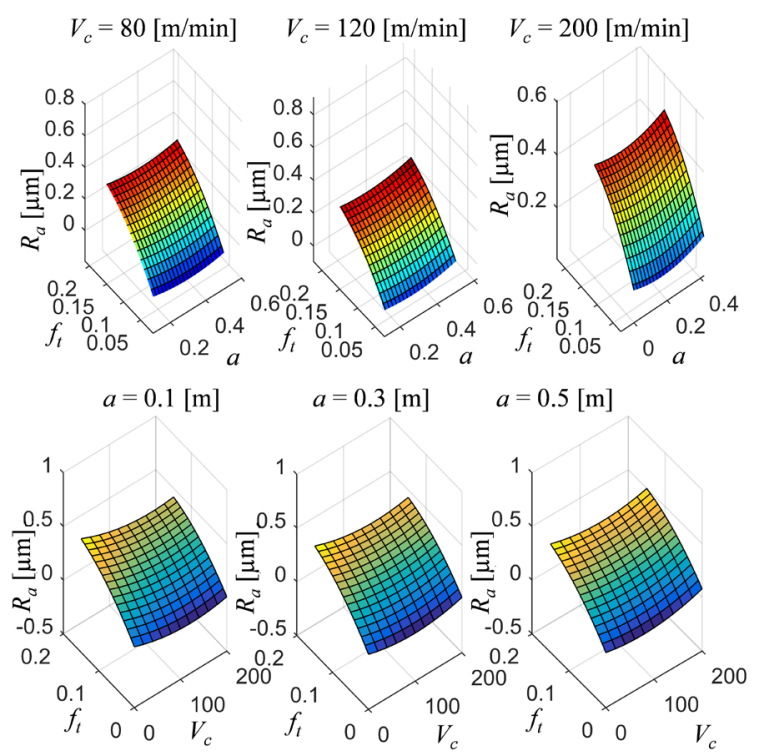

Fig. 4. Effect of cutting conditions on surface roughness

The surface roughness values exhibited decreasing tendency with increasing of axial depth of cut from 0 $\mathrm{mm}$ to about $0.3 \mathrm{~mm}$, but when the axial depth of cut increases from about $0.3 \mathrm{~mm}$ to $0.5 \mathrm{~mm}$, the tendency of surface roughness was reversed. Similarly, the surface roughness decreases with increasing of cutting speed from $0 \mathrm{~m} / \mathrm{min}$ to about $130 \mathrm{~m} / \mathrm{min}$, and with the cutting speed increases from about $130 \mathrm{~m} / \mathrm{min}$ to $200 \mathrm{~m} / \mathrm{min}$, the tendency of surface roughness is also increasing. So, to improve the surface roughness in the face-milling process of SKD61 hard steel, with regard to machining conditions, it was proposed that as the feed rate decreases, the axial depth of cut is about 0.3 $\mathrm{mm}$, and the cutting speed is about $130 \mathrm{~m} / \mathrm{min}$.

\subsection{Analysis for the Feed Force's Amplitude}

\subsubsection{Analysis of Variance for the Feed Force's Amplitude}

The ANOVA results for the amplitude of the feed force was illustrated in Table 5; the contributions of each factor on the amplitude of feed force were listed in the last column. It seems that the most important factor affecting the amplitude of feed force was the axial depth of cut $(72.89 \%)$. The second factor influencing the amplitude of feed force was feed rate (16.78\%). The third factor influencing the surface roughness was cutting speed (4.96\%).

Table 5. Results of ANOVA for feed force's amplitude

\begin{tabular}{|c|c|c|c|c|c|c|}
\hline \multicolumn{4}{|c|}{$\begin{array}{l}\text { Number of obs: } 27 \\
\text { Root MSE: } 15.9447\end{array}$} & \multicolumn{3}{|c|}{$\begin{array}{r}\text { R-squared: } 0.9953 \\
\text { Adj R-squared: } 0.9846\end{array}$} \\
\hline Source & SS & DOF & MS & F-value & $\begin{array}{l}\text { Prob } \\
>\mathrm{F}\end{array}$ & $\begin{array}{c}\text { Contr. } \\
{[\%]}\end{array}$ \\
\hline Model & 427244.87 & 18 & 23735.83 & 93.36 & 0.0000 & \\
\hline$V_{c}$ & 21301.93 & 2 & 10650.97 & 41.89 & 0.0001 & 4.96 \\
\hline$a$ & 312903.54 & 2 & 156451.77 & 615.29 & 0.0000 & 72.89 \\
\hline$f_{t}$ & 72015.59 & 2 & 36007.80 & 141.63 & 0.0000 & 16.78 \\
\hline$V_{c} \times a$ & 1122.92 & 4 & 280.73 & 1.10 & 0.4175 & 0.26 \\
\hline$V_{c} \times f_{t}$ & 2063.01 & 4 & 515.75 & 2.03 & 0.1831 & 0.48 \\
\hline$a \times f_{t}$ & 17837.86 & 4 & 4459.47 & 17.54 & 0.0005 & 4.16 \\
\hline Error & 2033.86 & 8 & 254.23 & & & 0.47 \\
\hline Total & 429278.72 & 26 & 16510.72 & & & 100 \\
\hline
\end{tabular}

\subsubsection{Regression and Verification of the Feed Force's Amplitude Model}

The most suitable regression of amplitude of feed force was a quadratic regression as given in Eq. (2). The compared results of measured values and predicted values of feed force's amplitudes were described in Fig. 5. It seems that the predicted results were very close to the measured results. The $R^{2}$ values of the equations obtained with the quadratic regression model for feed force's amplitude were found to be $98.74 \%$. So, the quadratic regression model is the most suitable regression of amplitude of the feed force.

$$
\left\{\begin{aligned}
A_{F_{f}}= & 44.3740-0.9807 \times V_{c}+275.4722 \times a \\
& +617.9998 \times f_{t}+0.3819 \times V_{c} \times a \\
& +3.3500 \times V_{c} \times f_{t}+3673.333 \times a \times f_{t} \\
& +0.0039 \times V_{c}^{2}-61.8055 \times a^{2}-4655.555 \times f_{t}^{2} \\
R^{2}= & 98.74 \%, \quad R_{A d j}^{2}=98.08 \%
\end{aligned}\right.
$$

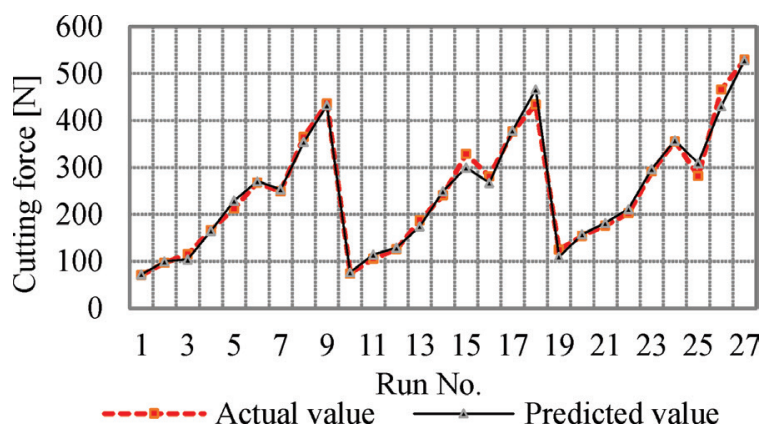

Fig. 5. Measured and predicted results of feed force's amplitude 


\subsubsection{Parametric Influence on Amplitude of Feed Force}

The variation of feed force's amplitude corresponding to the axial depth of cut and feed rate is described in Fig 6. This figure shows clearly that the feed force's amplitude increases with the increasing axial depth of cut and feed rate. This can be explained by the fact that when the axial depth of cut and feed rate increase, which increases the volume of chip thickness, and volume of chip thickness is directly proportional to cutting forces. Thus, the cutting forces' amplitude increases.

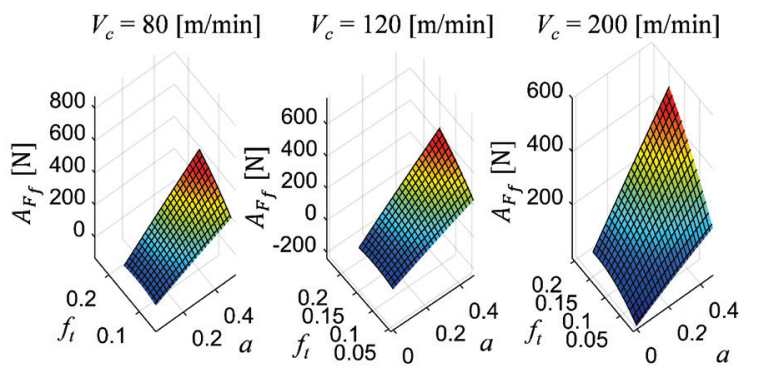

Fig. 6. Effect of cutting conditions on feed force's amplitude

\subsection{Analysis for Normal Force's Amplitude}

\subsubsection{Analysis of Variance for Normal Force's Amplitude}

The values of Table 6 show that the quadratic model is the most suitable of normal force amplitude and the contributions of each factor on the amplitude of feed force are listed in the last column.

Table 6. Results of ANOVA for Normal force's amplitude

\begin{tabular}{lrrrrrrr}
\hline $\begin{array}{l}\text { Number of obs: } 27 \\
\text { Root MSE: } 7.3608\end{array}$ & & & \multicolumn{3}{c}{ R-squared: 0.9958} \\
Adj R-squared: 0.9864
\end{tabular}

Clearly, the most important factor affecting on the amplitude of the normal force was the axial depth of cut $(70.04 \%)$. The second factor influencing the amplitude of normal force was the feed rate $(23.90$
$\%)$. The cutting speed has little effect on the amplitude of normal force $(0.27 \%)$.

\subsubsection{Regression and Verification of Normal Force's Amplitude}

The regression of amplitude of the normal force was a quadratic regression, as given in Eq. (3). The compared results of the measured values and predicted values of normal force's amplitudes are described in Fig. 7, which shows that the predicted results were very close to the measured results. The $R^{2}$ values of the equations obtained by quadratic regression model for feed force's amplitude were found to be $99.42 \%$. So, the quadratic regression model is the most suitable regression of amplitude of normal force.

$$
\left\{\begin{aligned}
A_{F_{n}}= & 2.7917-0.0818 \times V_{c}+253.8473 \times a \\
& +69.4723 \times f_{t}-0.5063 \times V_{c} \times a \\
& +0.8194 \times V_{c} \times f_{t}+2014.1660 \times a \times f_{t} \\
& +0.00075 \times V_{c}^{2}-112.9167 \times a^{2}-240.0002 \times f_{t}^{2}, \\
R^{2} & =99.42 \%, \quad R_{A d j}^{2}=99.11 \%
\end{aligned}\right.
$$

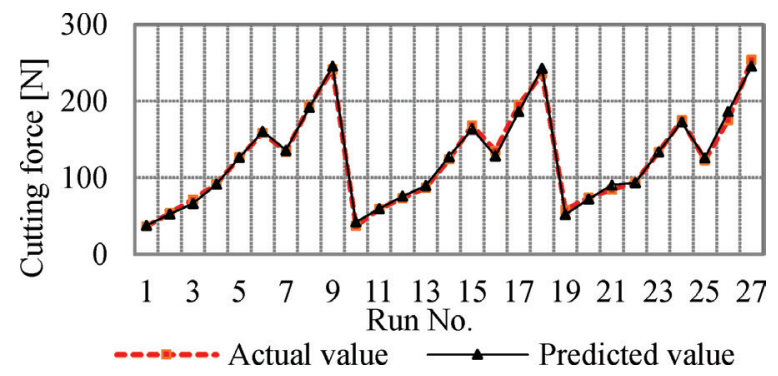

Fig. 7. Measured and predicted results of normal force's amplitude

\subsubsection{Parametric Influence on Amplitude of Normal Force}

The tendency of normal force's amplitude is the same as that of the feed force. The variation of the normal force's amplitude corresponding to the axial depth of cut and feed rate is described in Fig. 8, which shows that the normal force's amplitude increases with increasing of the axial depth of cut and feed rate. This is a result of the fact that when the axial depth of cut and feed rate increase, that results increase in the volume of chip thickness, and if the volume of chip thickness increases, the cutting forces' amplitude will also increase. 


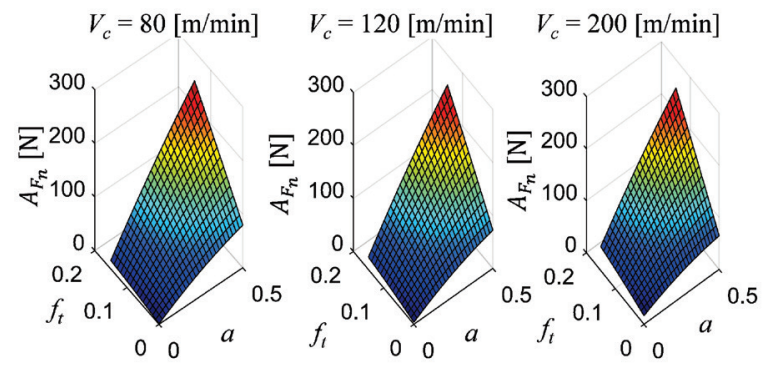

Fig. 8. Effect of cutting conditions on normal force's amplitude

\subsection{Analysis for Axial Force's Amplitude}

\subsubsection{Analysis of Variance for Axial Force's Amplitude}

The ANOVA results for the amplitude of axial force are described in Table 7. The contributions of each factor on the amplitude of axial force were calculated and listed in the last column. It seems that the influence of each factor on the amplitude of axial force was quite similar (feed rate: $33.74 \%$, cutting speed: $30.42 \%$, and axial depth of cut: $23.93 \%$ ).

Table 7. Results of ANOVA for Axial force's amplitude

\begin{tabular}{lcccccc}
\hline $\begin{array}{l}\text { Number of obs: } 27 \\
\text { Root MSE: } 38.5002\end{array}$ & & & \multicolumn{3}{c}{$\begin{array}{r}\text { R-squared: } 0.9698 \\
\text { Adj R-squared: } 0.902\end{array}$} \\
\hline Source & SS & DOF & MS & F-value & $\begin{array}{c}\text { Prob } \\
>\mathrm{F}\end{array}$ & $\begin{array}{c}\text { Contr. } \\
{[\%]}\end{array}$ \\
\hline Model & 381253.26 & 18 & 21180.74 & 14.29 & 0.0003 & \\
\hline$V_{c}$ & 119568.02 & 2 & 59784.01 & 40.33 & 0.0001 & 30.42 \\
\hline$a$ & 94068.87 & 2 & 47034.43 & 31.73 & 0.0002 & 23.93 \\
\hline$f_{t}$ & 132632.98 & 2 & 66316.49 & 44.74 & 0.0000 & 33.74 \\
\hline$V_{c} \times a$ & 21406.58 & 4 & 5351.65 & 3.61 & 0.0577 & 5.45 \\
\hline$V_{c} \times f_{t}$ & 9411.24 & 4 & 2352.81 & 1.59 & 0.2676 & 2.39 \\
\hline$a \times f_{t}$ & 4165.57 & 4 & 1041.39 & 0.7 & 0.6118 & 1.06 \\
\hline Error & 11858.14 & 8 & 1482.27 & & & 3.02 \\
\hline Total & 393111.40 & 26 & 15119.67 & & & 100 \\
\hline
\end{tabular}

\subsubsection{Regression and Verification of Axial Force's Amplitude}

The most suitable regression of axial force' amplitude was a quadratic regression as given in Eq. (4). The $R^{2}$ values of the equations obtained by quadratic regression model for axial force's amplitude were found to be $93.74 \%$. The compared results of measured values and predicted values of feed force's amplitudes are described in Fig. 9, which shows that the tendencies and the values of predicted results were very close to the tendencies and the values of measured results. So, the quadratic regression model is the most suitable regression of amplitude of axial force.

$$
\left\{\begin{aligned}
A_{F_{a}}= & 40.9349+0.1876 \times V_{c}+206.9375 \times a \\
& -188.6806 \times f_{t}+2.6045 \times V_{c} \times a \\
& +9.1569 \times V_{c} \times f_{t}+1099.5830 \times a \times f_{t} \\
& -0.0019 \times V_{c}^{2}-542.5695 \times a^{2}+1465.5550 \times f_{t}^{2}, \\
R^{2}= & 93.74 \%, \quad R_{A d j}^{2}=90.42 \%
\end{aligned}\right.
$$

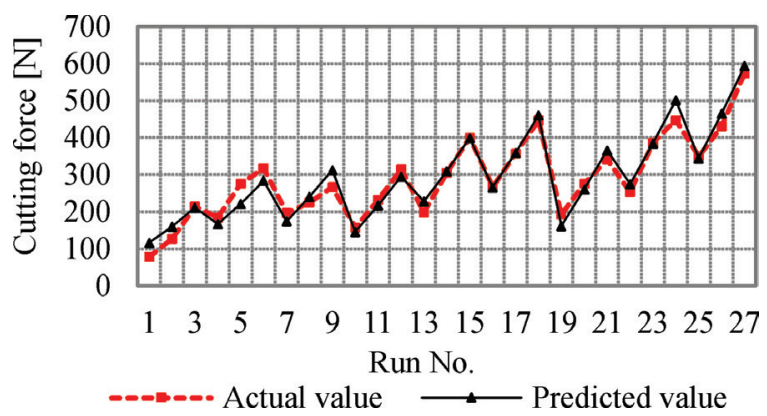

Fig. 9. Measured and predicted results of axial force's amplitude

\subsubsection{Parametric Influence on Amplitude of Axial Force}

The tendency of axial force's amplitude is also the same as that of the feed force. Fig. 10 presents the variation of axial force's amplitude corresponding to axial depth of cut and feed rate. Figure 10 revealed that the axial force's amplitude increases with increase in axial depth of cut and feed rate. The reason for this tendency is the same as for the feed force's amplitude and normal force's amplitude as well.

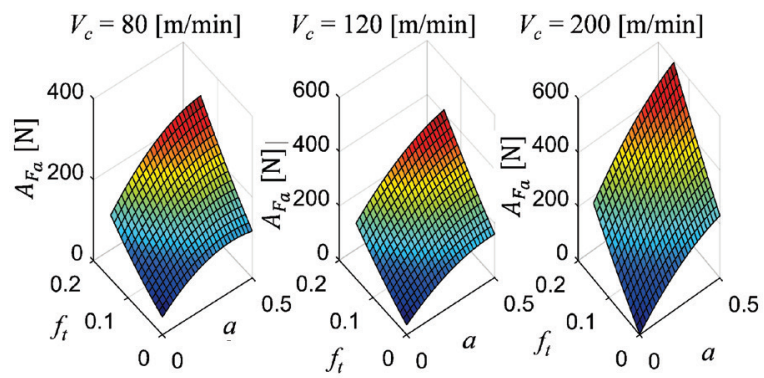

Fig. 10. Effect of cutting conditions on axial force's amplitude

\subsection{The Relationship of Cutting Force and Surface Roughness in Milling}

In this paper, the relationship between cutting force's amplitude and surface roughness was also investigated. It seems that this relationship has not been studied previously. The amplitudes of cutting forces and the surface roughness were drawn in 
one diagram, as shown in Fig. 11. It seems that the tendency of the surface roughness is the same as that of the cutting force's amplitudes. As seen from this figure, if the cutting force's amplitudes increase, the surface roughness increases; if the cutting force's amplitudes decrease, the surface roughness also decreases. These could be explained that in finishface milling processes, at the high stable cutting conditions with small vibrations, the chip thickness is quite stable, it makes the machining surface quite smooth, and so the surface roughness is often small (good surface). Furthermore, in this process, because the chip thickness is quite stable, the cutting forces in all directions are often quite stable, and these make the amplitudes of cutting forces smaller than those at other machining conditions. In the opposite cases, when the milling conditions are unstable cutting with chatter or large vibrations, the chip thickness will be unstable; it makes the surface and cutting force more unstable as well, and so that the amplitudes of cutting forces and surface roughness will be larger than that of other milling conditions. Thus, in this study, it is seen that there is the same tendency of output parameters in machining processes. By this reason, in this study, the optimal value was determined for surface roughness that is one of the most important values to improve the quality of machining product, as presented in Section 2.6.

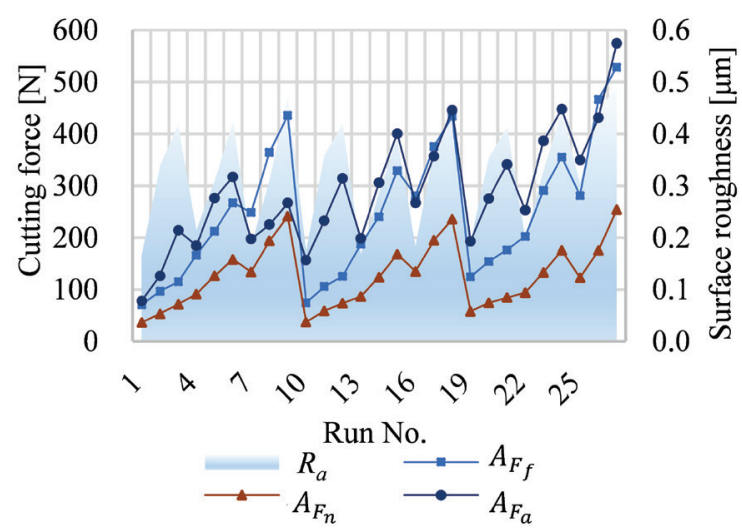

Fig. 11. The relationship between cutting force's amplitude and surface roughness

\subsection{Optimization of Cutting Conditions}

\subsubsection{Estimation of Optimum Surface Roughness by ANOVA Method}

The lowest value of surface roughness is very important for quality improvement of the machining product and lowering production costs. In this study, the quadratic regression model of surface roughness as presented by Eq. (1) that was used to find the optimized values of surface roughness and machining parameters. By using MATLAB R2013 $\mathrm{a}^{\mathrm{TM}}$ software, the optimized results of machining parameters were obtained as $f_{\text {val }}=0.1531, \quad x=[113.0595,0.2636,0.0500], \quad$ where $f_{\text {val }}$ is the optimal value of the surface roughness as presented by Eq. (1). And, $x$ are the values of variables in Eq. (1) when surface roughness equals to $f_{\text {val }}$.

Thus, with the ANOVA method, the optimal parameters of milling process were determined as cutting speed: $V_{c}=113.0595 \mathrm{~m} / \mathrm{min}$, axial depth of cut: $a=0.2636 \mathrm{~mm}$, feed rate: $f_{t}=0.0500 \mathrm{~mm} /$ flute.

And, the optimization value of surface roughness was $R_{a}=0.1531 \mu \mathrm{m}$.

\subsubsection{Analysis of the Signal-to-Noise (S/N) Ratio}

Using the Taguchi method, the optimal values of control factor were determined by analysis of the signal-to-noise ratio. The lowest value of surface roughness is very important to improve the machining product, so the smaller-the-better equation was used for calculation of the $S / N$ ratio [31]. The values of the $S / N$ response for observations of surface roughness were listed in Table 8 and shown in Fig. 12.

Table 8. The S/N response for surface roughness

\begin{tabular}{lcccc}
\hline \multirow{2}{*}{ Factor } & \multicolumn{3}{c}{ Mean S/N ratio } & \multirow{2}{*}{ Delta } \\
\cline { 2 - 4 } & Level 1 & Level 2 & Level 3 & \\
\hline$V_{c}$ & 9.8245 & 10.0299 & 9.5829 & 0.4469 \\
\hline$a$ & 10.0552 & 10.2519 & 9.1301 & 1.1218 \\
\hline$f_{t}$ & 13.4388 & 8.5886 & 7.4099 & 6.0289 \\
\hline
\end{tabular}

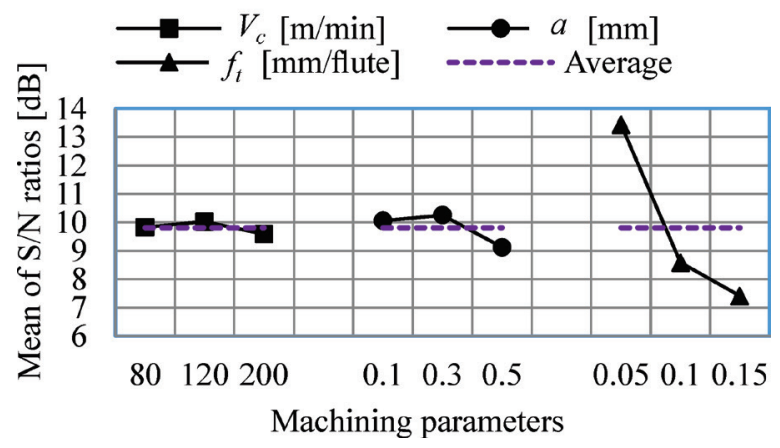

Fig. 12. Main effects of each factor on surface roughness

With Taguchi techniques, the best level of each control factor was determined according to the highest $S / N$ ratio at the level of that control factor [32]. With these techniques, from the values of Table 7 and Fig. 12 , the level and $S / N$ ratios for the factors giving the 
best $R_{a}$ value were specified as factor cutting speed (level 2, $S / N=10.029881 \mathrm{~dB}$ ), factor axial depth of cut (level 2, $S / N=10.251945 \mathrm{~dB}$ ), factor feed rate (level $1, S / N=13.438819 \mathrm{~dB}$ ). So, with the Taguchi method, the optimum value of surface roughness was obtained at a cutting speed of $140 \mathrm{~m} / \mathrm{min}$, a depth of cut of 0.3 $\mathrm{mm}$, and a feed rate of $0.05 \mathrm{~mm} / \mathrm{flute}$. The value of surface roughness with optimized values is 0.1605 $\boldsymbol{\mu m}$. The comparison results of the optimization values of the two methods were described in Table 9. The optimized results between the ANOVA method and Taguchi method are quite close together. However, the ANOVA method gave the better result regarding surface roughness. So, this method can be applied to improve the surface quality in finished face milling the SKD61 hard steel.

Table 9. The optimized results of ANOVA and Taguchi method

\begin{tabular}{lccc}
\hline \multirow{2}{*}{$\begin{array}{c}\text { Machining } \\
\text { parameters }\end{array}$} & \multicolumn{2}{c}{ Optimization values } & Differences \\
\cline { 2 - 3 } & ANOVA method & Taguchi method & [\%] \\
\hline$V_{c}$ & 113.0595 & 140 & 19.24 \\
\hline$a$ & 0.2636 & 0.3 & 12.13 \\
\hline$f_{t}$ & 0.05 & 0.05 & 0.00 \\
\hline$R_{a}[\mu \mathrm{m}]$ & 0.1605 & 0.1531 & 4.58 \\
\hline
\end{tabular}

\section{CONCLUSIONS}

In this study, an experimental method was performed to investigate the influence of cutting conditions on the surface roughness and cutting force's amplitudes. Depending on the analysis of experimental results, the conclusions of this study can be drawn as follows.

1. The most important factor affecting the surface roughness was the feed rate $(86.594 \%)$, while the most important factor affecting on the cutting force's amplitudes was the axial depth of cut (72.891\% for feed force amplitude and 70.039 $\%$ for normal force amplitude). The other factors affect differently on the surface roughness and cutting force's amplitudes.

2. The cutting force's amplitudes increase with the increasing of the axial depth of cut and feed rate. While the surface roughness decreases with the decreasing of the feed rate, with increasing of axial depth of cut from $0 \mathrm{~mm}$ to about $0.3 \mathrm{~mm}$, and with the increasing of cutting speed from $0 \mathrm{~m} /$ $\min$ to about $130 \mathrm{~m} / \mathrm{min}$. Furthermore, the surface roughness increases with increasing of feed rate, with increasing of axial depth of cut from about $0.3 \mathrm{~mm}$ to $0.5 \mathrm{~mm}$, and with increasing of cutting speed from about $130 \mathrm{~m} / \mathrm{min}$ to $200 \mathrm{~m} / \mathrm{min}$. To improve the surface roughness in the face-milling process of SKD61hard steel, with regards to machining conditions, it was proposed that the feed rate decreases, the axial depth of cut is about $0.3 \mathrm{~mm}$, and the cutting speed is about $130 \mathrm{~m} /$ min.

3. The tendency of the surface roughness is the same as that of the cutting force's amplitudes. So, the optimal value was determined for surface roughness, which is one of the most important values to improve the quality of machining product.

4. The Taguchi and ANOVA methods can be used to find the optimal value of surface roughness. In this study, the optimized result from ANOVA method is better than that of the Taguchi method. The optimum value of surface roughness is $0.1531 \mu \mathrm{m}$, which was obtained at cutting speed of $113.0595 \mathrm{~m} / \mathrm{min}$, at an axial depth of cut of $0.2636 \mathrm{~mm}$, and a feed rate of $0.05 \mathrm{~mm} /$ flute.

The cutting force amplitude and surface roughness models can be applied in the adaptive control processes of $\mathrm{CNC}$ milling to improve the machining surface and reduce the cutting force and will be the futuristic study of future research.

\section{ACKNOWLEDGEMENTS}

The authors appreciate the generous assistance from the CNC Lab for the dynamometer in the cutting force measurement experiments. Thanks also extend to the support from the Faculty of Mechanical Engineering, Hanoi University of Industry (HaUI), Vietnam.

\section{REFERENCES}

[1] Fernández-Abia, A.I., Barreiro, J., López de Lacalle, L.N., Martínez-Pellitero, S. (2012). Behavior of austenitic stainless steels at high speed turning using specific force coefficients. International Journal Advance Manufacturing Technology, vol. 62, no. 5-8, p. 505-515, DOl:10.1007/s00170-011-3846-9.

[2] Guibert, N., Paris, H., Rech, J. (2008). A numerical simulator to predict the dynamical behavior of the self-vibratory drilling head. International Journal of Machine Tools and Manufacture, vol. 48, no. 6, p. 644-655, D0l:10.1016/j. ijmachtools.2007.11.003.

[3] Dang, J.-W., Zhang, W.-H., Yang, Y., Wan, M. (2010). Cutting force modeling for flat end milling including bottom edge cutting effect. International Journal of Machine Tools and Manufacture, vol. 50, no. 11, p. 986-997, Dol:10.1016/j. ijmachtools.2010.07.004.

[4] Rouzrokh, A., Yi-HsuanWei, C., Erkorkmaz, K., Pilliar, R.M. (2010). Machining Porous Calcium Polyphosphate Implants for Tissue Engineering Applications. International 
Journal of Automation Technology, vol 4, no. 3, p. 291-302, DOI:10.20965/ijat.2010.p0291.

[5] Altintas, Y. (2012). Manufacturing Automation: Metal cutting Mechanics, Machine Tool Vibrations, and CNC Design, 2nd ed. Cambridge University Press, Cambridge, Dol:10.1017/ Св09780511843723.

[6] Wang, M., Gao, L., Zheng, Y. (2014). An examination of the fundamental mechanics of cutting force coefficients. International Journal of Machine Tools and Manufacture, vol. 78, p. 1-7, D0I:10.1016/J.ijmachtools.2013.10.008.

[7] Kao, Y.-C., Nguyen, N.-T., Chen, M.-S., Su, S.-T. (2015). A prediction method of cutting force coefficients with helix angle of flat-end cutter and its application in a virtual threeaxis milling simulation system. The International Journal of Advanced Manufacturing Technology, vol. 77no. 9-12, p. 1793-1809, D0I:10.1007/s00170-014-6550-8.

[8] Narita, H. (2013) A Determination Method of Cutting Coefficients in Ball End Milling Forces Model. International Journal of Automation Technology, vol. 7, no. 1, p. 39-44, DOI:10.20965/ijat.2013.p0039.

[9] Tukora, B., Szalay, T. (2011). Real-time determination of cutting force coefficients without cutting geometry restriction. International Journal of Machine Tools and Manufacture, vol. 51, no. 12, p. 871-879, Dol:10.1016/j. ijmachtools.2011.08.003.

[10] Gao, G., Wu, B., Zhang, D., Luo, M. (2013). Mechanistic identification of cutting force coefficients in bull-nose milling process. Chinese Journal of Aeronautics, vol. 26, no. 3, p. 823-830, D0I:10.1016/j.cja.2013.04.007.

[11] Gradišek, J., Kalveram, M., Weinert, K. (2004). Mechanistic identification of specific force coefficients for a general end mill. International Journal of Machine Tools \& Manufacture, vol. 44, no. 4, p. 401-414, D0l:10.1016/j. ijmachtools.2003.10.001.

[12] Suresh, P., Venkatesan, R., Sekar, T., Elango, N., Sathiyamoorthy, V. (2014). Optimization of intervening variables in microEDM of SS 316L using a genetic algorithm and response-surface methodology. Strojniski vestnik - Journal of Mechanical Engineering, vol. 60, no. 10, p. 656-664, D0I:10.5545/sv-jme.2014.1665.

[13] Ponnuvel, S., Senthilkumar, N. (2019). A study on machinability evaluation of Al-Gr-B 4 C MMC using response surface methodology-based desirability analysis and artificial neural network technique. International Journal of Rapid Manufacturing, vol. 8, no. 1-2, p. 95-122, D0l:10.1504/ ijrapidm.2019.10017666.

[14] Tsoukalas, V.D. (2008). Optimization of porosity formation in AlSi9Cu3 pressure die casting using genetic algorithm analysis. Material \& Design, vol. 29, no. 10, p. 2027-2033, Dol:10.1016/j.matdes.2008.04.016.

[15] Hsu, Q.C., Do, A.T. (2013). Minimum porosity formation in pressure die casting by Taguchi method. Mathematical Problems in Engineering, art. ID: 920865, p. 1-9, DOl:10.1155/2013/920865.

[16] Rao, S.R., Padmanabhan, G. (2012). Application of Taguchi methods and ANOVA in optimization of process parameters for metal removal rate in electrochemical machining of $\mathrm{Al} / 5 \% \mathrm{SiC}$ composites. International Journal of Engineering Research and Applications, vol. 2, no. 3, p. 192-197.

[17] Perec, A., Pude, F., Kaufeld, M., Wegener, K. (2017). Obtaining the selected surface roughness by means of mathematical model based parameter optimization in abrasive waterjet cutting. Strojniski vestnik - Journal of Mechanical Engineering, vol. 63, no. 10, p. 606-614, D0l:10.5545/sv-jme.2017.4463.

[18] Motorcu, A.R. (2010). The optimization of machining parameters using the Taguchi method for surface roughness of AISI 8660 hardened alloy steel. Strojniski vestnik - Journal of Mechanical Engineering, vol. 56, no. 6, p. 391-401

[19] Kumar, P., Chauhan, S.R., Pruncu, C.I., Gupta, M.K., Pimenov, D.Y., Mia, M., Gill, H.S. (2019). Influence of different grades of CBN inserts on cutting force and surface roughness of AISI H13 die tool steel during hard turning operation. Materials, vol. 12, no. 1, p. 177, Dol:10.3390/ma12010177.

[20] Siddiqueea, A.N., Khan, Z.A., Goel, P., Kumar, M., Agarwal, G., Khan, N.Z. (2014). Optimization of deep drilling process parameters of AISI 321 steel using Taguchi method. Procedia Materials Science, vol. 6, p. 1217-1225, D0l:10.1016/j. mspro.2014.07.195.

[21] Prasanna, J., Karunamoorthy, L., Raman, V.M., Prashanth, S., Chordia, D.R. (2014). Optimization of process parameters of small hole dry drilling in Ti-6Al-4V using Taguchi and grey relational analysis. Measurement, vol. 48, p. 346-354, DOI:10.1016/j.measurement.2013.11.020.

[22] Çiçek, A., Kıvak, T., Samtaş, G. (2012). Application of Taguchi method for surface roughness and roundness error in drilling of AISI 316 stainless steel. Strojniški vestnik - Journal of Mechanical Engineering, vol. 58, no. 3, p. 165-174, DOl:10.5545/sv-jme.2011.167.

[23] Ghani, J.A., Choudhury, I.A., Hassan, H.H. (2004). Application of Taguchi method in the optimization of end milling parameters. Journal of Materials Processing Technology, vol. 145, no. 1, p. 84-92, D0l:10.1016/S0924-0136(03)00865-3.

[24] Turgut, Y., Çinici, H., Sahin, I., Findik, T. (2011). Study of cutting force and surface roughness in milling of Al/Sic metal matrix composites. Scientific Research and Essays, vol. 6, no. 10, p. 2056-2062, D0l:10.5897/SRE10.496.

[25] Lin, T.-R. (2002). Experimental design and performance analysis of TiN coated carbide tool in face milling stainless steel. Journal of Materials Processing Technology, vol. 127, no. 1, p. 1-7, D0I:10.1016/S0924-0136(02)00026-2.

[26] Kivak. T. (2014). Optimization of surface roughness and flank wear using the Taguchi method in milling of Hadfield steel with PVD and CVD coated inserts. Measurement, vol. 50, p. 19-28, Dol:10.1016/j.measurement.2013.12.017.

[27] Ozcelik, B., Bayramoglu, M. (2006). The statistical modeling of surface roughness in high-speed flat end milling. International Journal of Machine Tools and Manufacture, vol. 46, no. 12-13, p. 1395-1402, D0l:10.1016/j.ijmachtools.2005.10.005.

[28] Karakas, M.S., Acır, A., Übeyli, M., Ögel, B. (2006). Effect of cutting speed on tool performance in milling of $\mathrm{B} 4 \mathrm{Cp}$ reinforced aluminum metal matrix composites. Journal of Materials Processing Technology, vol. 178, no. 1-3, p. 241246, D0I:10.1016/J.jmatprotec.2006.04.005.

[29] Jayakumar, K., Mathew, J., Joseph, M.A. (2013). An investigation of cutting force and tool-work interface 
temperature in milling of $\mathrm{Al}-\mathrm{SiCp}$ metal matrix composite. Proceedings of the Institution of Mechanical Engineers, Part B: Journal of Engineering Manufacture, vol. 227, no. 3, p. 362374, DOI:10.1177/0954405412472887.

[30] Montgomery, D.C. (2001). Design and Analysis of Experiments. $5^{\text {th }}$ ed., Wiley, New York.

[31] Roy, R.K. (2001). Design of Experiments Using the Taguchi Approach: 16 Steps to Product and Process Improvement. John Wiley \& Sons, New York.

[32] Noordin, M.Y., Venkatesh, V.C., Sharif, S., Elting, S., Abdullah, A. (2004). Application of response surface methodology in describing the performance of coated carbide tools when turning AISI 1045 steel. Journal of Materials Processing Technology, vol. 145, no. 1, p. 46-58, D0l:10.1016/S09240136(03)00861-6.

[33] Arumugam, S., Sriram, G., Rajmohan, T. (2014). Multiresponse optimization of epoxidation process parameters of rapeseed oil using response surface methodology (RSM)based desirability analysis. Arabian Journal for Science and Engineering, vol. 39, no. 3, p. 2277-2287, D0l:10.1007/ s13369-013-0789-5.

[34] Abbas, A.T., Pimenov, D.Y., Erdakov, I.N., Mikolajczyk, T., El Danaf, E.A., Taha, M.A. (2017). Minimization of turning time for high-strength steel with a given surface roughness using the Edgeworth-Pareto optimization method. The International Journal of Advanced Manufacturing Technology, vol. 93, no. 5-8, p. 2375-2392, D0I:10.1007/s00170-017-0678-2.

[35] Abbas, A., Pimenov, D., Erdakov, I., Taha, M., El Rayes, M., Soliman, M. (2018). Artificial intelligence monitoring of hardening methods and cutting conditions and their effects on surface roughness, performance, and finish turning costs of solid-state recycled Aluminum alloy 6061 chips. Metals, vol. 8, no. 6, p. 394, D0l:10.3390/met8060394. 